\title{
Penggunaan Metode Peer Teaching Dalam Pembelajaran Gitar dan Keyboard di Gereja Toraja Jemaat Gandangbatu Timur Klasis Gandangbatu
}

\author{
Musa Masing \\ Universitas Mercu Buana Yogyakarta \\ musamasing4@gmail.com
}

\begin{abstract}
Abstrak
Peer Teaching adalah suatu proses pembelajaran dengan melibatkan teman sebaya. Proses pembelajaran tersebut bisa berlaku untuk jenis kegiatan apapun termasuk pembelajaran musik. Peer Teaching kebanyakan gereja tidak mengembangkan hal tersebut dan memilih untuk mencari pelatih dari luar dibandingkan memberdayakan pemuda gereja yang sangat potensial. Tujuan penelitian ini adalah untuk mendeskripsikan metode Peer Teaching dalam pembelajaran musik (Gitar dan Keyboard) yang dilakukan di Jemaat Gandangbatu Timur Klasis Gandangbatu. Subjek dalam penelitian ini ada 10 Orang pemuda yang dibagi menjadi 2 kelompok yaitu kelompok Musik Gitar dan Kelompok Musik Keyboard. Metode yang dipakai dalam penelitian ini adalah metode penelitian kualitatif dengan pendekatan deskriptif. Hasil penelitian menunjukkan bahwa proses pembelajaran musik dengan metode Peer Teaching dilaksanakan dengan memulai konsep dasar dalam bermusik. Output dari Peer Teaching ini adalah terlatihnya pemuda gereja yang bisa melayani dalam jemaat (Bagian Musik)
\end{abstract}

Kata Kunci : Peer Teching, Musik, Pembelajaran

\begin{abstract}
Peer Teaching is a learning process by involving peers. The learning process can apply to any type of activity, including learning musik. Peer Teaching in most churches did not develop this and chose to seek outside coaches rather than empowering church youth with great potential. The purpose of this study was to describe the Peer Teaching method in learning guitar and keyboard which was carried out in the Gandangbatu Timur Congregation, Klasis Gandangbatu. Subjects in this study were 10 youths who were divided into 2 groups, namely the Musik Guitar Group and the Musik Keyboard Group. The method used in this research is a qualitative research method with a descriptive approach. The results showed that the music learning process using the Peer Teaching method was carried out by starting the basic concepts in music. The output of this Peer Teaching is the training of church youths who can serve in the congregation (Music Section)
\end{abstract}

Keywords : Peer Teaching, Music and Learning 


\section{Pendahuluan}

\section{Pada zaman sekarang dikenal} dengan zaman postmodern. Semua media dan inforasi bisa diperoleh dengan cepat dari berbagi sudut dan tempat baik itu dari media social, lingkungan sekitar serta dari orang-orang tertentu yang mempunyai keahlian khusus dalam bisang tertentu termasuk dalam hal musik. Dalam pembelajaran musik, berbagai cara bisa dilakukan untuk bisa melatih kemampuan dan meningkatkan skill bermain musik salah satunya adalah dengan metode pembelajaran teman sebaya (Peer Teaching) Pembelajaran musik dengan metode peer teaching adalah pembelajaran seni yang berusaha menggali serta mengembangkan potensi estetika anak serta mempengaruhi anak agar mempunyai nilai estetika sehingga dapat memperhalus budi pekerti, karena dalam seni terdapat unsur- unsur keindahan, keteraturan, kedisiplinan dan dinamika ${ }^{1}$.

Purnomo dan Subagyo menjelaskan bahwa tutor sebaya adalah metode pengajaran yang memberi kesempatan pada peserta didik untuk mengajarkan dan berbagai ilmu pengetahuan atau (Jakarta: 2011) keterampilan pada peserta didik yang lain ${ }^{2}$. Sedangkan Muntasir menjelaskan bahwa tutor sebaya adalah metode pembelajaran dimana beberapa anak ditunjuk atau ditugaskan untuk membantu temannya yang mengalami kesulitan dalam belajar agar temannya tesebut bisa memahami materi dengan baik. ${ }^{3}$

Pembelajaran teman sebaya (Peer Teaching)dinilai sangat efektif terutama dalam hal pembelajarn musik karena dapat memberi rasa nyaman pada anak karena pada umumnya hubungan antara teman lebih dekat dibandingkan hubungan peserta didik dengan guru. ${ }^{4}$ Hasil penelitian Roscoe \& Thi juga menjelaskan bahwa Manfaat Proses pembelajaran teman sebaya memberikan kesempatan dan mendorong pada anak mempelajari sesuatu dengan baik, dan pada waktu yang sama ia menjadi narasumber bagi yang lain. ${ }^{5}$ Inilah yang menyebabkan Pembelajaran peer teaching merupakan cara yang efektif untuk

2 Purnomo \& Subagyo. Terampil Bermusik. (Jakarta:2010)

3 Muntasir, M. Saleh. 2009. Pembelajaran Terprogram. Jakarta: Rajawali

${ }^{4}$ Ainoer Roffiq dkk, "Media Musik dan Lagu pada Proses Pembelajaran", Jurnal Pendidikan Dasar Indonesia, 2017, hlm. 38.

${ }^{5}$ Roscoe, R.D., \& Chi, M.T.H. Understanding Tutor Learning: Knowledge Building And Knowledgetelling In Peer Tutors' Explaination and Questions.(Review of Education Research:2007) 
menghasilkan kemampuan mengajar teman sebaya dalam bermain music.

Berdasarkan hasil Observasi yang dilakukan di Gereja Toraja Jemaat Gandangbatu Timur, Pembelajaran Peer Teaching sudah berlangsung selama 2 Bulan mulai Bulan Februari dan Maret tahun 2021. Proses pembelajaran yang menyenangkan serta tidak kaku menjadikan pembelajaran tersebut menjadi terarah. Hal ini senada dengan yang disampaikan oleh Djamarah bawa Yang paling penting dari penggunaan metode pembelajaran tutor sebaya adalah melatih siswa/ anak agar dapat memberanikan diri berbicara di depan anak yang lain yang dalam hal ini adalah melatih siswa mengajar teman-temannya, sehingga para siswa dapat merasakan kenikmatan dan ketidaknyamanan dalam mengajar. ${ }^{6}$ Selain itu pembelajaran Peer Teaching merangsang fungsi social anak untuk belajar berani serta belajar bersosialisasi secara terbuka.

Pembelajaran Peer Teaching juga dilaksanakan oleh kelompok remaja di Gereja Toraja Jemaat Gandangbatu Timur dalam bermain musik yaitu Keyboard dan Gitar. Hal tersebut dilakukan dengan memberdayakan pemuda gereja sebagai

\footnotetext{
${ }^{6}$ Djamarah,S,B. Guru dan Anak Didik dalam Interaksi Edukatif (Suatu Pendekatan Teoretis Psikologis). (Jakarta: 2010).
}

sumber daya yang bisa dikembangkan secara internal. Pembelajaran Peer Teaching untuk pembelajaran musik dan keyboard sendiri menjadi program kerja Persekutuan Pemuda Gereja Toraja Jemaat Gandangbatu Timur tahun 2021. Dalam proses pembelajaran tersebut, dilaksanakan dengan 2 kelas dengan tutor yang berbeda yaitu Kelas Keyboard dan Kelas Gitar. Kegiatan tersebut mendapatkan dukungan secara penuh dari Majelis Jemaat setempat dengan memberdayakan pemuda masa kini yang akan menjadi Generasi masa depan gereja disamping itu merealisasikan fungsi gereja sebagai Pelayan Allah dimana setiap orang dipanggil untuk melayani sesuai bakat dan telenta yang dimiliki termasuk bermain musik.

Penelitian tentang Peer Teaching sudah banyak diteliti, namun terdapat perbedaan-perbedaan dalam tulisan ini dengan tulisan sebelumnya misalnya Penelitian yang dilakukan oleh Yofi Nisa Febrianti dengan judul penelitian Peer Teaching (TUTOR SEBAYA) Sebagai Metode Pembelajaran Untuk Melatih Siswa Mengajar hasil penelitiannya adalah Tutor sebaya (peer teaching) ini memudahkan belajar, siswa berpartisipasi aktif, dan dapat memecahkan masalah bersama-sama, sehingga pemerataan pemahaman terhadap materi pembelajaran yang 
diberikan dapat tercapai. Perbedaan Penelitian ini dengan penelitian sekarang adalah penelitian ini menggunakan Systemic Literatur Review sedangkan penelitian sekarang menggunaka Penelitian Kualitatif dengan pendekatan Deskriptif.

Penelitian yang dilakukan oleh Nurmiati dalam judul penelitian Keefektifan Penggunaan Metode Pembelajaran Tutor Sebaya (PEER-TEACHING) Dalam Kemampuan Membaca Memahami Bahasa Jerman Siswa Kelas XI IPA SMA NEGERI 1 Bontonompo Kabupaten Gowa. Hasil penelitian menujukkan bahwa penggunaan metode pembelajaran tutor sebaya (PeerTeaching) efektif dalam kemampuan membaca memahami bahasa Jerman siswa kelas XI IPA SMA Negeri 1 Bontonompo Kabupaten Gowa.

Perbedaan penelitian ini dengan penelitian sekarang adalah penelitian ini menggunakan metode Quasi experimental design (eksperimental-semu)Non equivalent control group sedangkan penelitian ini menggunakan desain penelitian kualitatif dengan pendekatan deskriptif. subjek dalam penelitian terdahulu adalah siswa kelas XI IPA SMA Negeri 1 Bontonompo sedangkan subjek dalam penelitian ini adalah Pemuda Gereja dengan tingkat umur dan jenjang pendidikan yang berbeda-beda .
Perbedaa-perbedaan tersebut serta melihat urgensi metode Peer Teaching dalam pembelajaran musik membuat hal ini layak untuk diteliti. Harapannya adalah metode ini bisa digunakan oleh berbagai gereja dalam melakukan pemberdayaan pemuda atau remaja gereja sebagai sumber daya yang bisa digunakan dalam metode pembelajaran yang bukan hanya musik tetapi bisa juga untuk kegiatan lain sesuai bidang atau talenta anak.

\section{Metode}

Penelitian yang digunakan dalam penelitian ini adalah Kualitatif dengan jenis penelitian Studi Kasus. Mudjia Rahardjo mendefenisikan studi kasus sebagai suatu rangkaian kegiatan ilmiah yang dilakukan secara intensif, secara rinci, serta mendalam mengenai suatu peristiwa atau aktivitas seorang atau sekelompok orang. ${ }^{7}$ Penelitian studi kasus dipilih karena hasil studi yang bersifat komprehensif, intens, rinci dan mendalam serta lebih diarahkan pada upaya menelaah masalah-masalah atau fenomena yang bersifat kontemporer, kekinian, sehingga metode ini sangat tepat untuk penelitian ini. Subjek dalam Penelitian adalah Pemuda dan Remaja Gereja Toraja

\footnotetext{
${ }^{7}$ Mudjia Rahardjo, "Studi Kasus Dalam
} Penelitian Kualitatif: Konsep Dan Prosedurnya" (Malang: Universitas Islam Negeri Malang, 2013), http://respository.uinmalang.ac.id.//1104/studikasus-dalampenelitian-kualitatif. 
Jemaat Gandangbatu Timur berjumlah 10 Orang. Teknik pengumpulan data yang dilakukan adalah dengan melakukan wawancara, Observasi serta dokumentasi. Dalam penelitian kualitatif desktiptif peneliti merupakan intrumen utama (key instrumen) dalam pengumpulan data dan menginterpretasi data dengan dibimbing oleh pedoman wawancara dan pedoman observasi. Hal mana senada dengan yang diungkapkan Moleong bahwa dalam peneliti kualitatif, peneliti sendiri atau dengan bantuan orang lain merupakan alat pengumpul data utama. $^{8}$ Analisis data dalam penelitian ini dilakukan melalui tiga kegiatan yang terjadi secara bersamaan yaitu reduksi data, penyajian data, dan penarikan kesimpulan atau verifikasi data.

\section{Hasil dan Pembahasan}

Beberapa aspek yang ditemukan dalam pembelajaran dengan metode Peer Teaching di Jemaat Gandangbatu Timur yang dijabarkan berdasarkan jenis musik yaitu Gitar dan Keyboard. Ada 2 Grub yang dibentuk dengan masing-masing 1 orang tutor yang sudah mahir memainkan salah satu alat musik tersebut baik itu Gitar maupun Keyboard

1. Peer Teaching dengan Alat Musik Gitar

\footnotetext{
${ }^{8}$ Maleong, L J. Metodologi Penelitian Kualitatif. (Bandung:2000)
}

Jenis alat musik gitar yang digunakan adalah Gitar Clasic. Pemilihan gitar akustik dalam pembelajaran ini dengan tujuan selain mudah dipelajari juga banyak diantara anggota kelompok yang mempunyai alat musik yang sama.

Jenis-jenis kegiatan Peer Teaching dalam bermain musik gitar adalah

a) Melakukan tahap persiapan. Dalam tahap persiapan ini seorang anak diberikan pemahaman mengenai cara memegang gitar dengan benar, posisi duduk, serta cara memetik gitar berdasarkan jenis kunci yang dimainkan. Setelah posisi duduk dan memegang gitar dilakukan, hal berikut yang dilakukan adalah belajar menekan senar gitar yang mungkin untuk beberapa anak akan merasa sakit pada bagian ujung jari karena tidak terbiasa tetapi hal itu akan berkurang seiring dengan keseringan memetik dan menekan senar gitar. Penekanan senar gitar terus dilakukan secara berulang sampai menghasilkan suara gitar dengan nyaring.

b) Tahap memainkan Gitar. Dalam tahap memainkan gitar menjadi tujuan utama pelaksanaan peer teaching ini. Langkah awal yang dilakuukan adalah pengenalan 


\begin{abstract}
beberapa pengetahuan dasar misalnya pengenalan sangkar nada kunci $G$, tanda ulang, tanda kromatis, birama dan tanda diam atau istirahat. Penjabaran langkah awal sebagai berikut
\end{abstract}

1) Pengenalan sangkar nada. Yaitu tempat meletakkan not yang terdiri atas 5 buah garis dan 4 buah spasi yang dihitung muali dari awal. Garis tersebut harus memenuhi persyaratan berjumlah lima buah, berjarak sama, sejajar satu sama lain, dan merupakan kesatuan.

\section{Contoh Gambar Sangkar Nada}

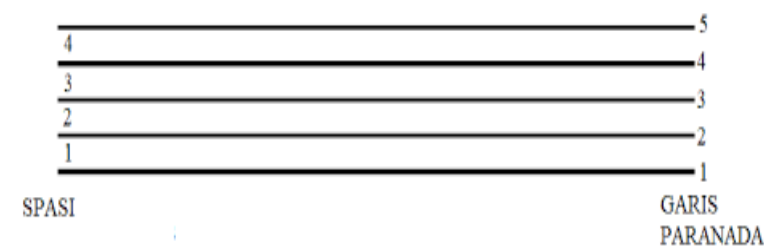

Gambar 1. Dokumentasi pribadi Prayitno (2021)

2) Pengenalan Kunci $G$ yang merupakan tanda yang menunjukkan letak titik nada tertentu. Contoh Gambarnya Kunci $G$ yang diajarkan sebagai berikut

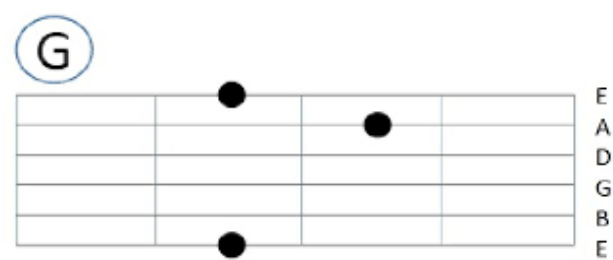

Gambar 2. Dokumentasi pribadi Prayitno (2021)

3) Pengenalan Kunci birama. Contoh Kunci Birama sebagai berikut

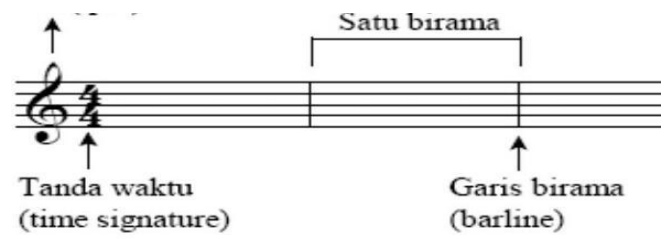

Gambar 3. Dokumentasi Pribadi Prayitno (2021)

4) Pengenalan Tanda Kromatis. Pengenalan tanda kromatis dengan tujuan untuk menaikkan dan menurunkan titik nada pokok setengah nada atau laras. Titik nada yang dinaikkan atau diturukan adalah notasi musik yang umum yaitu c,d,e,f,g,a. Semua titik nada pokok yang diberi tanda krois dibaca dengan akhiran is

5) Pengenalan not dan tanda diam. Not yang biasa disebut Notasi, sedangkan tanda istirahat adalah bentuk tertentu dari istirahat.. Contoh gambar Not dan tanda diam sebagai berikut 


\begin{tabular}{|c|c|c|c|}
\hline Nama Not & Bentuk Not & Tanda Istirahat & Nillai \\
\hline Not Penuh & $\mathbf{0}$ & $=$ & 4 Ketuk \\
\hline Not $1 / 2$ & & & 2 Ketuk \\
\hline Not $1 / 4$ & & 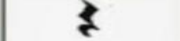 & 1 Ketuk \\
\hline Not $1 / 8$ & & & 1/2 Kotuk \\
\hline Not $1 / 16$ & & & 1/4 Ketuk \\
\hline Not $1 / 32$ & & & 1/8 Ketuk \\
\hline
\end{tabular}

Gambar 4. Dokumentasi pribadi Prayitno (2020)

2. Peer Teaching dengan alat musik Keyboard.

Untuk peer teaching menggunakan alat musik Keyboard. Jenis keyboard yang digunakan adalah Yamaha PS 710. Pemilihan jenis alat musik tersebut karena ada beberapa dari anggota jemaat yang memiliki jenis alat musik yang sama.

Langkah-langkah Peer Teaching dalam permainan alat musik keyboard adalah

a. Posisi duduk. Posisi duduk yang benar adalah selalu tegak, dan posisi tangan pada saat bermain keyboard adalah menekuk sedikit jari-jari seolah sedang memegang bola. Posisi yang salah dalam bermain keyboard dapat mengakibatkan lekas capek dan berakhir dengan permainan yang kurang bagus.
Contoh posisi duduk yang benar adalah sebagai berikut

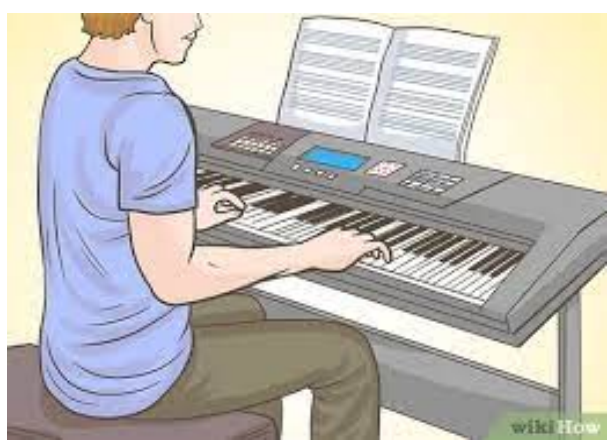

Gambar 5. Dokumentasi Pribadi Jimmy (2021)

b. Pengetahuan tentang tuuts dan Interval serta latihan menindis (Finger)

Latihan fingering ini ditujukan agar posisi jari dan tangan kita saat bermain keyboard ada dalam posisi yang benar. Juga untuk bentuk jari-jari kita saat bermain di atas tuts keyboard ada dalam posisi sempurna. Contoh Gambarnya sebagai berikut

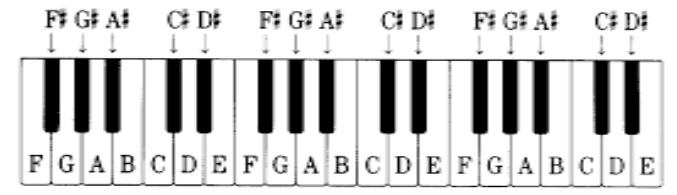

Gambar 6. Dokumentasi Jimmy (2021)

Selanjutnya setelah mengetahui tuuts tersebut, langka selanjutnya adalah posisi penggunaan jari pada saat memainkan keyboard. Contoh posisi tangan saat memainkan keyboard ada pada gambar berikut 


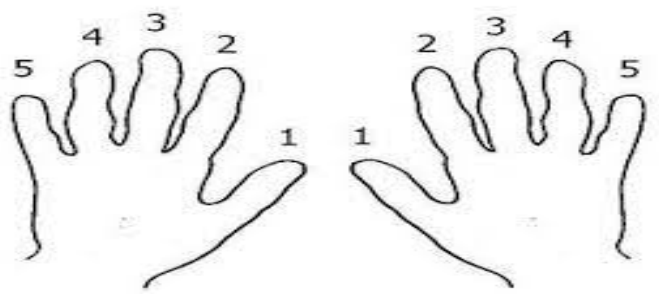

Gambar 6. Dokumentasi Pribadi Jimmy (2020)

C. Membaca not Balok. Pengetahuan tentang cara membaca not balok sangat dibutuhkan untuk memudahkan dalam membaca partitur laguatau cord sebuah lagu. Untuk mempermudah dalam mengingat letak atau posisi tuts pada keyboard, maka diperlukan banyak latihan secara rutin tiap harinya. Nada dasar terdiri dari C D E F G A B C (do-re-mi-fa-sol-la-si-do) atau biasa ada yang menulis 12345667 (biasa ditulis dibuku-buku lagu guna mempermudah), adapun nilai jarak nada seperti contoh dibawah ini

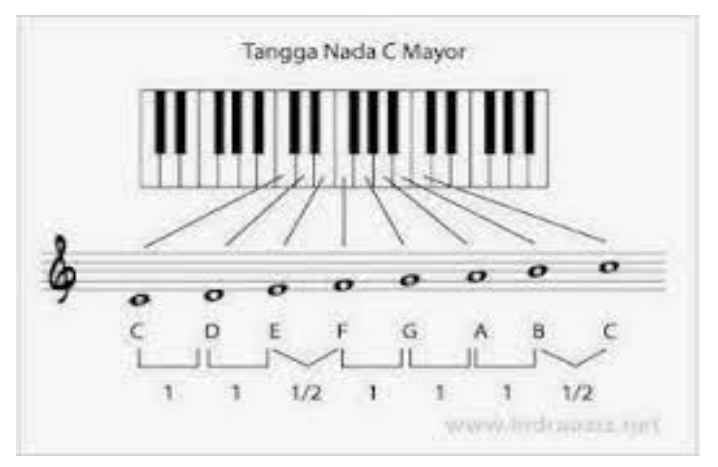

Gambar 7. Dokumentasi Pribadi Jimmy (2021) d. Pengenalan tempo. Tempo dalam hal ini adalah berapa lama not itu dimainkan. Ketukan itu terdiri dari berbagai macam, cotohnya 4/4, 3/4, 2/4. Simulasinya sebagai berikut : memainkan musik dengan ketukan 4/4 dalam not penuh. Misalnya, kita memencet nada C sambil kita menghitung 1234 , hitungan ke 4 tangan kita diangkat dari tuts dan masuk hitungan 1 kita tekan lagi tutsnya dan begitu lagi seterusnya. Contoh gambarnya sebagai berikut

\begin{tabular}{|c|c|c|}
\hline Simbol & Nama & Nilai \\
\hline Not Penuh & 4 Ketuk \\
\hline Not $1 / 2$ & 2 Ketuk \\
\hline & Not $1 / 4$ & 1 Ketuk \\
\hline & Not $1 / 8$ & $1 / 2$ Ketuk \\
\hline & Not $1 / 162$ & $1 / 4$ Ketuk \\
\hline
\end{tabular}

Gambar 8. Dokumentasi pribadi Jimmy (2021)

Setelah pengenalan dasar tersebut selelsai dilakukan, langkah selanjutnya adalah dengan mendampingi anak untuk belajar secara lengsung dengan 1 lagu. Output yang diharapkan dari Peer Teaching ini adalah anak diharapkan mengetahui dasar-dasar dalam bermain keyboard termasuk teknik memainkan tempo dan isntriumen lagu serta bisa membawakan 1 
lagu rohani. Proses pembelajaran yang terus berlangsung dengan sebuah eyaknan bahwa skill atau keahlian bermain alat musik akan berkembang seiring dengan seringnya memainkan alat musik tersebut disamping mendapatkan panduan dan arahan dari teman sebaya yang ahli dalam musik tersebut.

\section{Kesimpulan}

Generasi Muda adalah generasi yang diharapkan menjadi generasi masa depan gereja, Bangsa dan Negara. Generasi mudah yang mempunyai kreativitas serta semangat yang tinggimenjadikan Gereja menjadi Terang yang sesungguhnya di tenggah-tengah dunia ini. Kreativitas itulah yang bisa dikembangkan dalam jemaat terutama bagi pemuda yang memiliki potensi atau skill bermain musik (Gitar dan Piano). Memberikan kesempatan untuk mengambil bagian dalam pelayanan jemaat termasuk pembelajaran dengan model peer teaching akan membuat akan secara psikologis melatih kepercayaan diri dan secara social mampu untuk menumbuhkan leadership serta responsibility.

Metode Peer Teaching di Jemaat Gandangbatu Timur dimulai dengan pengenalan dasar alat musik Keyboard dan Gitar. Hal tersebut tentuya masih bisa dikembangkan seiiring dengan bertambahkanya pengetahuan serta skill bermain musik anak. Penggunaan Metode Peer Teaching juga menjadi wadah bagi gereja untuk memberdayakan anggota jemaat secara internal serta memupuk rasa persaudaraan dalam lingkup pemuda. Hal tersebut tentunya positif dan dinilai memberikan kontribusi yag besar bagi kelanjutan gereja sehingga kehadiran gereja di tengah-tengah masyarakat membawa dampak yang baik.

\section{Kepustakaan}

Arikunto, Suharsimi. 2012. Prosedur Penelitian Suatu Pendekatan Praktik Edisi (Revisii VI). Jakarta: Rineka Cipta

Djamarah, Syaiful Bahri. 2010. Guru dan Anak Didik dalam Interaksi Edukatif (Suatu Pendekatan Teoretis Psikologis). Jakarta: Rineka Cipta.

Hendriana, E. C., Jacobus, A. 2016. Implementasi Pendidikan Karakter di Sekolah Melalui Keteladanan dan Pembiasaan. Kalbar: Jurnal Pendidikan Dasar Indonesia.

Moleong, L. J. (2011). Metodologi Penelitian Kualitatif. Jakarta: Remaja Rosda Karya.

Muntasir, M. Saleh. 2009. Pembelajaran Terprogram. Jakarta: Rajawali

Muskitta, Billy, Markus Wibowo, Erwin Sianturi. 2020. Profesionalitas Pelatih Dalam Pengembangan Kualitas Paduan Suara Nine's Voice di Sma Negeri 9 Manado. Manado: Clef: Jurnal Musik dan Pendidikan Musik. 
Rahardjo, M. 2012. Studi Kasus Dalam Penelitian Kualitatif: Konsep Dan Prosedurnya. Malang: Universitas Islam Negeri Malang, http://respository.uinmalang.ac.id.//11 04/studi-kasus-dalampenelitiankualitatif.

Purnomo \& Subagyo. 2010. Terampil Bermusik. Jakarta: Pusat Perbukuan Kementerian Pendidikan Nasional.

Roscoe, R.D., \& Chi, M.T.H. 2007. Understanding Tutor Learning: Knowledge Building And Knowledgetelling In Peer Tutors' Explaination and Questions. Review of Education Research, 77 (4): 534-574.

Roffiq, A., Qiram, I., Rubiono, G. 2017. Media Musik dan Lagu Pada Proses Pembelajaran. Jawa Timur: Jurnal Pendidikan Dasar Indonesia.

Syarifudin. 2011. Strategi Belajar Mengajar. Jakarta: Diadit Media. 